\title{
SUSPENDED AND BEDLOAD TRANSPORT IN THE SURF ZONE: IMPLICATIONS FOR SAND TRANSPORT MODELS
}

\author{
Joep van der Zanden'1, Dominic A. van der A², Tom O’Donoghue², David Hurther ${ }^{3}$, \\ Iván Cáceres ${ }^{4}$, Peter D. Thorne ${ }^{5}$, Jebbe J. van der Werf ${ }^{1,6}$, Suzanne J.M.H. Hulscher ${ }^{1}$ and \\ Jan S. Ribberink ${ }^{1}$
}

\begin{abstract}
This paper presents results obtained during a large-scale wave flume experiment focused at measuring hydrodynamics and sediment transport processes in the wave breaking region. The experiment involved monochromatic plunging breaking waves over a mobile bed barred profile consisting of $D_{50}=0.24 \mathrm{~mm}$ sand. Vertical profiles of velocity, turbulence, sand concentration and sand fluxes were measured at 12 cross-shore locations, covering the shoaling region up to the inner surf zone. Particularly high-resolution profiles were obtained near the bed within the wave bottom boundary layer, using an acoustic sediment concentration and velocity profiler (ACVP). Sheet flow concentration and particle velocities were measured at two locations near the bar crest using two conductivity-based concentration measurement tanks (CCM+). Total transport rates, obtained from the evolving bed profile measurements, were decomposed into suspended and bedload transport contributions across the bar. The present paper presents a summary of the key findings of the experiment, which are used to discuss existing approaches for modeling suspended and bed load transport in the surf zone.
\end{abstract}

Keywords: sand transport; breaking waves; wave flume experiment; boundary layer processes; sheet flow; morphodynamic models.

\section{INTRODUCTION}

The predictive capability of sand transport models for non-breaking waves has improved significantly during the last decades (van Rijn et al., 2013). For example, through inclusion of wave asymmetry effects into bedload transport models (Hoefel and Elgar, 2003; Van der A et al., 2013), morphodynamic models can now simulate sandbar migration in both onshore and offshore direction (Fernández-Mora et al., 2015). Nevertheless, an accurate numerical reproduction of complex near-shore morphodynamic processes, such as longer-term sandbar evolution or sand nourishment spreading, is not trivial and typically requires considerable model calibration (Walstra et al., 2012; Luijendijk et al., 2017).

Numerical modeling of near-shore morphodynamics may improve further by the inclusion of wave breaking effects on sand transport (van Rijn et al., 2013). One such effect is an increased (intermittent) suspension of sand particles from the bed following the arrival of turbulent vortices (Nadaoka et al., 1988; Scott et al., 2009; Zhou et al., 2017). Since breaking-generated turbulent kinetic energy may display a distinct intra-wave variation, especially under plunging waves, the suspension by wave breaking turbulence may drive a net wave-related suspended sediment flux (Yoon and Cox, 2012; Brinkkemper et al., 2017). Parameterizations have been developed to account for such wave breaking effects on sediment pick-up rates (Kobayashi and Johnson, 2001; Hsu and Liu, 2004; Spielmann et al., 2004) and net wave-related suspended sediment fluxes (Van Rijn, 2007). However, existing modeling approaches are generally not supported by a wide range of experimental observations.

This reflects that the effects of wave breaking on sand transport are still to a large extent unknown. In particular, most previous experiments involved local measurements at few cross-shore locations, which offers limited insights in the spatial distribution of sediment pick-up, deposition, and cross-shore advection. Furthermore, many studies involved irregular waves, which offer a good basis for a general understanding of wave breaking effects for a wide range of conditions, but offers limited detailed insights in how the complex intra-wave processes (e.g. time-varying turbulence, sand suspension) affect net sand transport. Finally, it is unknown whether wave breaking turbulence effects should be accounted for in bedload transport models, because measurements of bedload (sheet flow) transport in the wave breaking region are lacking.

This motivated a detailed study of hydrodynamic and sediment transport processes in the wave breaking region through large-scale wave flume experiments. Measurements were obtained with high spatial (horizontal and vertical) coverage across a sandy breaker bar. The near-bed region is sampled

\footnotetext{
${ }^{1}$ Water Engineering and Management, University of Twente, P.O. Box 217, Enschede, 7500 AE, Netherlands

${ }^{2}$ School of Engineering, University of Aberdeen, King's College, Aberdeen, AB24 3UE, United Kingdom

${ }^{3}$ LEGI-CNRS, University of Grenoble, Cedex 9, Grenoble, 38041, France

${ }^{4}$ CIEMLAB, Universitat Politècnica de Catalunya, C/Jordi Girona 1-3, Barcelona, 08034, Spain

${ }^{5}$ National Oceanographic Centre, 6 Brownlow Street, Liverpool, L3 5DA, United Kingdom

${ }^{6}$ Deltares, P.O. Box 177, Delft, 2600 MH, Netherlands
} 
with particularly high resolution, in order to study near-bed turbulence and sediment fluxes inside the wave bottom boundary layer and within the sheet flow layer. Experimental results of the campaign have been presented in a number of publications (Van der Zanden, 2016; Van der Zanden et al., 2016, Submitted); the present paper summarizes the main findings and discusses their implications for modeling surf zone sand transport in wave-averaged morphodynamic models.

\section{EXPERIMENTS}

The experimental set-up is presented in Fig. 1. The initial bed profile consisted of well-sorted medium sand $\left(D_{50}=0.24 \mathrm{~mm}\right)$ and followed a distinct breaker bar-trough configuration. The test section consisted of a mobile sand bed between $x=35$ to $68 \mathrm{~m}$; further shoreward, the beach profile was fixed with geotextile. The experiment involved regular waves with wave height $H=0.85 \mathrm{~m}$ and wave period $T=4$ s near the wave paddle at water depth $h=2.55 \mathrm{~m}$. One experimental repeat consisted of six 15 minute runs during which the mobile bed profile developed. After this 90-minute experiment the flume was drained and the initial bed profile was restored. This experimental procedure was repeated 12 times. Fig. 1 indicates definitions of cross-shore coordinate $x$ and vertical coordinates $z$ and $\zeta$, where the latter is the elevation with respect to the local bed level (i.e. $\zeta=z-z$ bed).

A mobile frame, custom-built for this project (Ribberink et al., 2014), was used to deploy the primary measurement instrumentation: an acoustic concentration and velocity profiler (ACVP) (Hurther et al., 2011), three acoustic Doppler velocimeters (ADVs), a six-nozzle transverse suction system (TSS), and a pressure transducer (PT). For each experimental repeat, the mobile frame was positioned to a different cross-shore location, resulting in a high spatial coverage of measurements (Fig. 1b). Two $\mathrm{CCM}^{+}$tanks (Van der Zanden et al., 2015) were installed slightly offshore from the bar crest to measure sheet flow concentration and particle velocity. The water surface elevation was measured by sidewall-deployed resistive wave gauges (RWGs) and PTs. Finally, echo sounders were used to measure the bed profile before each experiment and after every $2^{\text {nd }}$ run. The experiments and data processing steps are described in more detail in Van der Zanden et al. (2016; Submitted).
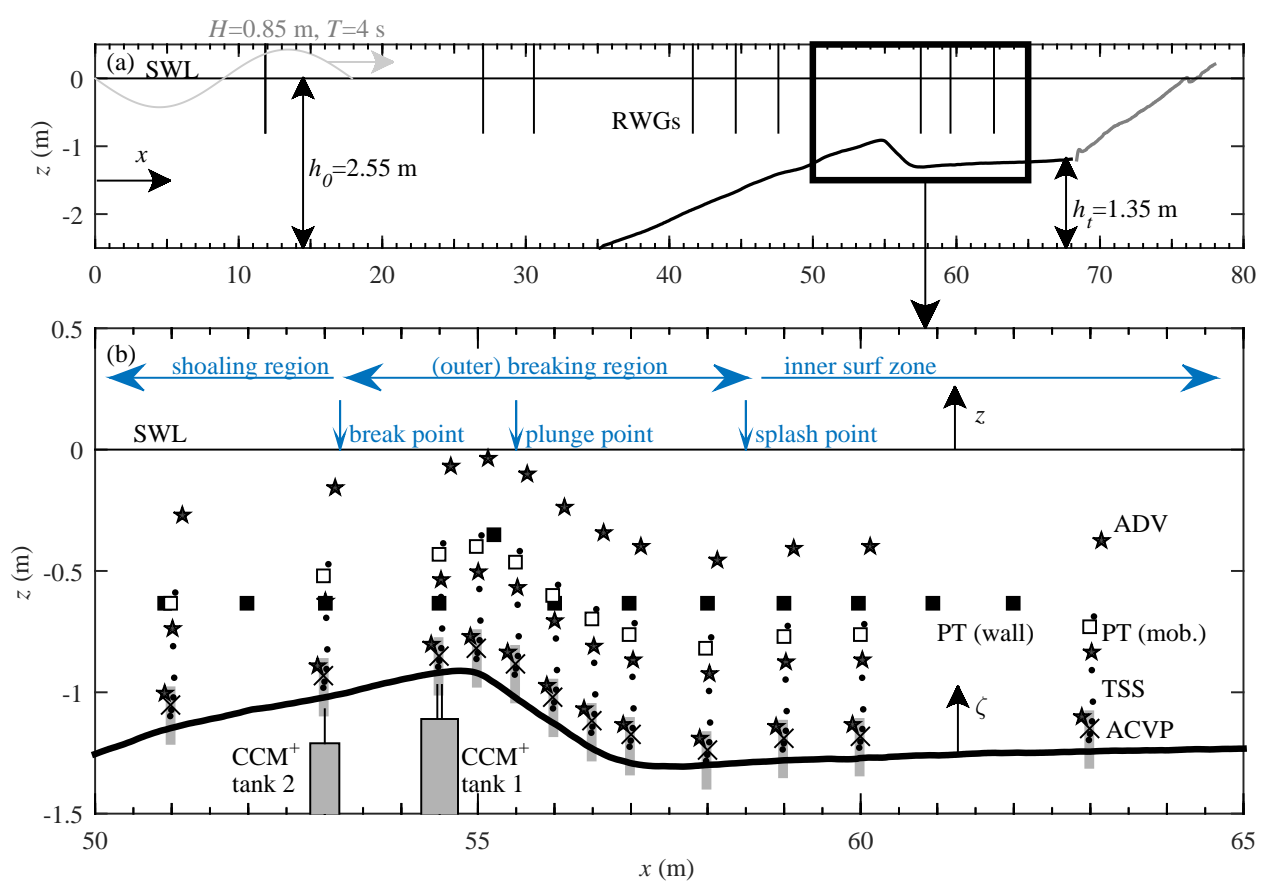

Figure 1. Experimental set-up: (a) bed profile (solid line) and locations of resistive wave gauges (vertical lines); (b) measurement locations of ADVs (star symbols), Transverse Suction System nozzles (black dots), pressure transducers (squares), ACVP (grey rectangles), and two $\mathrm{CCM}^{+}$tanks.

Waves were breaking over the bar crest and were of the plunging type. Fig. 1b depicts characteristic locations of the breaking process, i.e. the 'break point' where the wave starts to overturn $(x=53.0 \mathrm{~m})$; the 'plunge point' where the breaking jet hits the water surface $(x=55.5 \mathrm{~m})$; and the 'splash point' where 
the wave has transformed into a surf bore $(x=58.5 \mathrm{~m})$. This characterizes the shoaling region, breaking region and inner surf zone (Fig. 1b) following terminology by Svendsen et al. (1978).

\section{RESULTS}

\section{Hydrodynamics}

The outer-flow and wave bottom boundary layer (WBL) hydrodynamics are described in detail by Van der Zanden et al. (2016); the present section summarizes the main findings.

Fig. 2 a shows the maximum and minimum phase-averaged water surface elevation. The wave height decreases by approximately $50 \%$ between the break point and splash point. The time-averaged water surface elevation shows a net set-down before breaking, that transforms into net set-up in the inner surf zone $(x>58.5 \mathrm{~m})$. Fig. 2b shows that the breaking process further results in a reduction in the near-bed orbital velocity amplitude (also in part due to increasing water depth) and in an increase in offshoredirected undertow magnitude. The undertow is especially strong around $x=57.0 \mathrm{~m}$, reaching values of $0.5 \mathrm{~m} / \mathrm{s}$ at $\zeta=0.10 \mathrm{~m}$. The strong cross-shore gradients in bed-parallel undertow velocity $\bar{u}_{R}$ are indicative of a time-averaged velocity circulation with a strong bed-normal component, that directs towards the bed above the bar trough and towards the water surface above the bar crest.

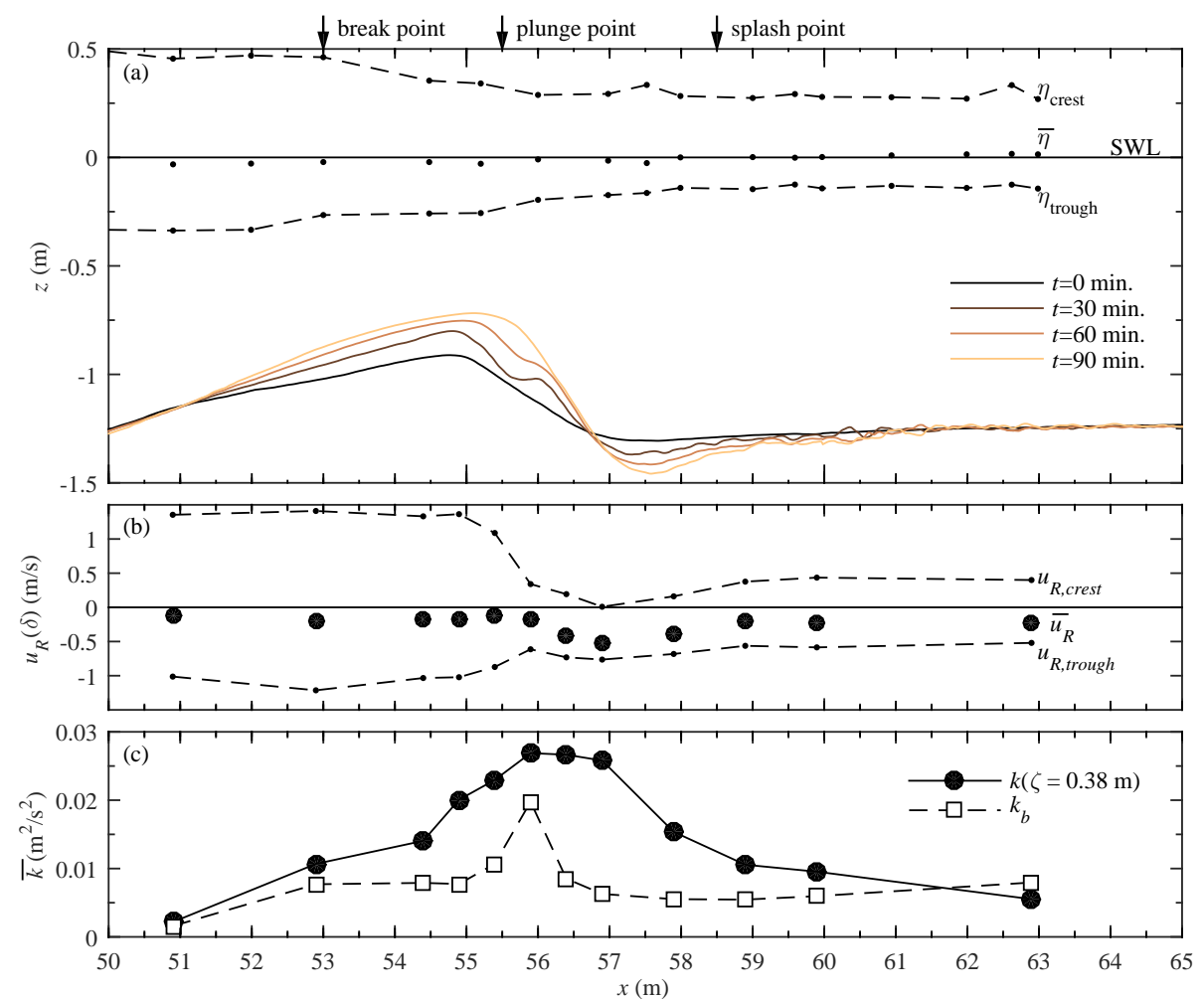

Figure 2. (a) Maximum, minimum and mean phase-averaged water surface level (dots and dashed lines) over the evolving bed profile (solid lines); (b) Maximum, minimum (dots and dashed line) and mean phase-averaged bed-parallel velocity $u_{R}$ (circles) at the WBL overshoot elevation $\delta$; (c) Time-averaged TKE at free-stream elevation $\zeta=z-z_{\text {bed }}=0.38 \mathrm{~m}$ (circles) and maximum time-averaged TKE inside the WBL (squares). The hydrodynamic measurements are taken during the first 15 minutes of the experiment $(t=0-15 \mathrm{~min}$.).

Fig. 2c shows the time-averaged turbulent kinetic energy (TKE) at free-stream elevation and inside the WBL. TKE increases by an order of magnitude in the breaking region $(x=53.0-58.0 \mathrm{~m})$ relative to the shoaling zone $(x=51.0 \mathrm{~m})$. This TKE increase occurs at both free-stream and WBL elevation and regardless of the reduction in the periodic velocities, which indicates that wave breaking is the main source for the TKE increase and which suggests that breaking-generated turbulence even invades the WBL.

\section{Suspended sand concentrations}

The analysis of suspended sediment processes herein focuses on sand concentration and horizontal sand fluxes at wave-averaged time scale. A more extensive analysis of suspended sediment processes, including intra-wave concentrations and fluxes, is given by Van der Zanden et al. (Submitted). 
Fig. 3 shows suspended sediment concentrations measured with TSS (circles). The profiles can be described with a power function (e.g. Kobayashi et al., 2005):

$$
C(\zeta)=C_{0}\left(\zeta / z_{\mathrm{a}}\right)^{-1 / m}
$$

Here, $C_{0}$ is a reference concentration at reference elevation $\zeta=z_{\mathrm{a}}$ close to the bed, and $m$ is a vertical mixing parameter. Fig. 3 (solid curves and background color contour) shows the inter- and extrapolated time-averaged concentration obtained by fitting Eq. 1 through the TSS measurements. We used a reference elevation $z_{\mathrm{a}}=0.005 \mathrm{~m}$, corresponding approximately to the top of the sheet flow layer which is considered the interface between the bed load and suspended load layers in this study.

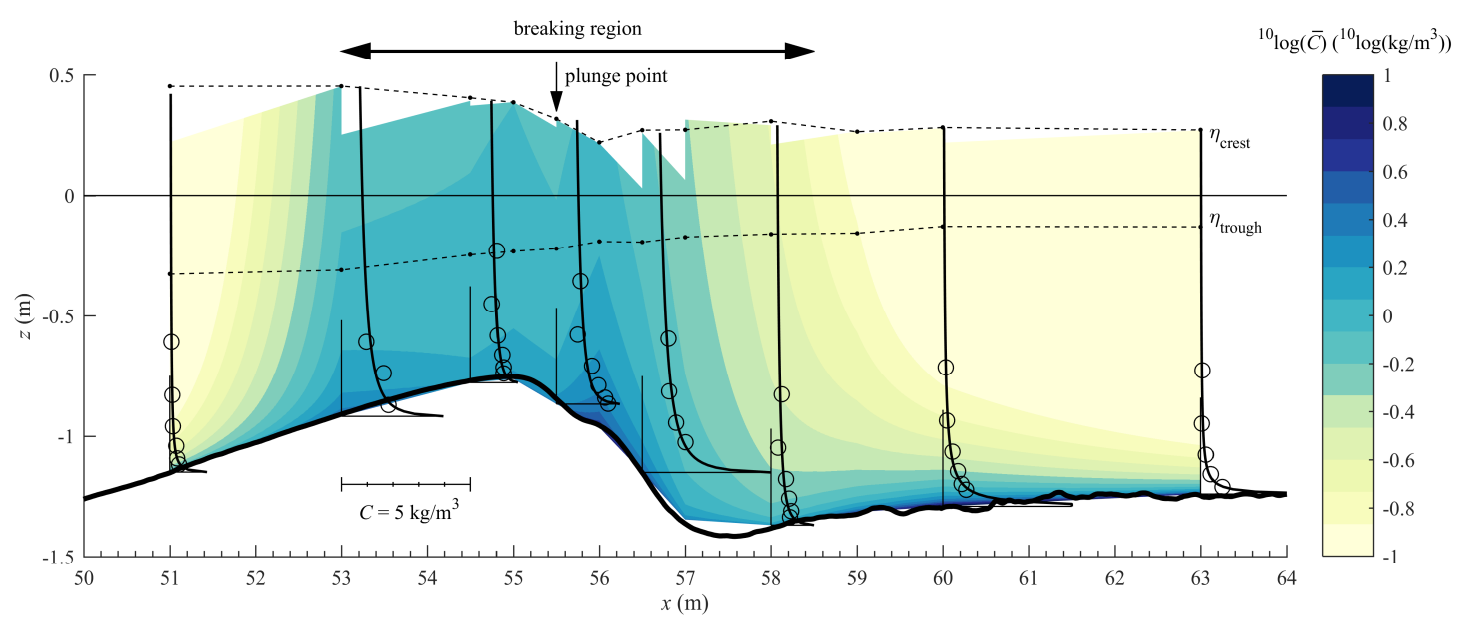

Figure 3. Time-averaged suspended sediment concentration. Open circles depict TSS measurements at eight cross-shore locations, solid curves depict fitted power function (Eq. 1). The background color contour shows the concentration field based on power-function fits at all 12 cross-shore locations. All measurements correspond to $t=45-60 \mathrm{~min}$.

Suspended sand concentrations vary by orders of magnitude in both horizontal and vertical direction. In the wave breaking region concentrations are up to two orders of magnitude higher in the breaking region relative to the shoaling zone and inner surf zone. Highest concentrations are measured close to the bed between the bar crest and bar trough $(x=55.0$ to $57.0 \mathrm{~m})$, i.e. in close vicinity of the plunge point at $x=55.5 \mathrm{~m}$. Strongest vertical mixing of suspended sediment occurs above the bar crest $(x=53.0$ to $56.0 \mathrm{~m}$ ). Two mechanisms are considered mainly responsible for this strong mixing: (i) advection by upward time-averaged velocities resulting from the two-dimensional undertow circulation; (ii) vertical diffusion by breaking-generated turbulence.

The reference concentration $C_{0}$ is widely used as bottom boundary condition in wave-averaged depth-resolving advection-diffusion models for suspended sand. $C_{0}$ is typically calculated based on the estimated bed shear stress by periodic and time-averaged horizontal velocities (e.g. Nielsen, 1986; Van Rijn, 2007). To assess the predictive capability of such models for the present study, Fig. 4a shows scatter plots of $C_{0}$ versus root-mean-square periodic velocity. No clear relation becomes apparent; especially the data points between $x=55.5-59.0 \mathrm{~m}$ show large variability. A similar analysis between $C_{0}$ and timeaveraged velocity $\bar{u}$ (not shown) did not reveal a clear trend either. This proves the limited predictive capability of $C_{0}$ models based on periodic and time-averaged velocity for the present breaking-wave dataset.

The reference concentration is not a physically measured concentration, but is instead a model concept for the bottom boundary condition that accounts for the physical vertical sand influx from the bedload to the suspension layer (i.e. the net pick-up). Close to the bed, where vertical time-averaged and orbital velocities are very small, the vertical sand flux is largely diffusive. For non-breaking waves, vertical sediment diffusion is driven by bed shear generated eddies. For the present study, external wave breaking turbulence has locally invaded the WBL. In order to assess whether the increase in near-bed turbulence affects the vertical diffusive sand flux (i.e. the pick-up), Fig. $4 \mathrm{~b}$ shows a scatter plot of $C_{0}$ versus the maximum wave-averaged TKE inside the WBL, $k_{\mathrm{b}}$. The positive correlation between both parameters suggests that wave breaking turbulence effectively enhances sediment entrainment from the bed. This is consistent with previous observations of (intermittent) suspension following breakinggenerated eddy arrival at the bed (Nielsen, 1984; Nadaoka et al., 1988; Scott et al., 2009), which has 
been physically explained by high instantaneous turbulent bed shear stresses (Cox et al., 1996; Zhou et $a l ., 2017)$ and by upward-directed pressure gradients in the bed that occur directly under large-scale rotational vortices (Sumer et al., 2013).

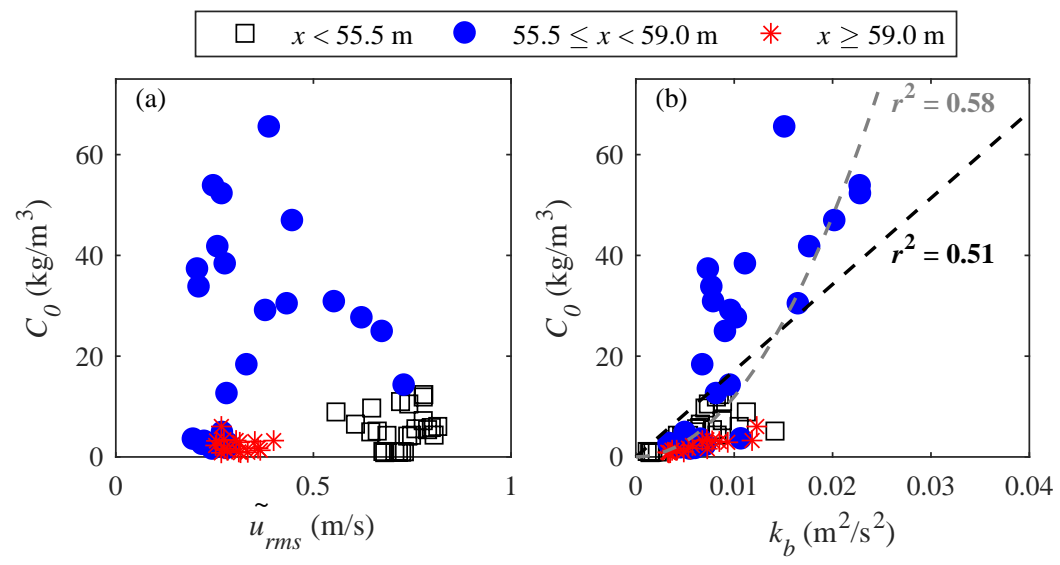

Figure 4. Reference concentration versus measured (a) root-mean-square periodic velocity and (b) timeaveraged TKE inside the WBL. $C_{0}$ is obtained by fitting Eq. 1 through time-averaged concentration profiles measured with ACVP. Data are clustered for three regions across the bar, i.e. offshore from the bar crest (squares), between bar crest and trough (circles) and at inner surf zone (asterisks). Panel b shows best-fit trend lines and corresponding $r^{2}$ based on a linear (black) and quadratic (grey) relation.

Additional analysis was done to assess to what extent the concentration at $\zeta=z_{\mathrm{a}}$ is controlled by local pick-up. Results (shown in Van der Zanden et al., Submitted) showed that the time-averaged concentration at $\zeta=z_{\mathrm{a}}$ is almost fully explained ( $\left.>90 \%\right)$ by local pick-up; contributions by horizontally advected sediment are minor. This suggests that models for time-averaged reference concentration may use only the local hydrodynamics as input and do not need to account for the spatially non-uniform hydrodynamics.

\section{Suspended sand flux}

Sand concentrations were also measured by ACVP through inversion of the acoustic backscatter intensity. These concentrations are collocated with velocity measurements, hence the ACVP provides the vertical profile of the instantaneous horizontal sand flux $\Phi_{x}=u C$. Fig. 5 (upper panels) shows the phase-averaged sand flux $\left\langle\Phi_{x}\right\rangle$ at five cross-shore locations. In the shoaling zone, the sand fluxes are largely contained inside the WBL (indicated by dashed line). In the wave breaking region, flux magnitudes increase at outer-flow elevations due to the much higher suspended sediment load relative to the shoaling zone. Sand flux magnitudes reduce at the inner surf zone, where both the suspended load and the phase-averaged velocities decrease.

The time-averaged (i.e. net) total sand flux $\bar{\Phi}_{x}$ was decomposed as:

$$
\bar{\Phi}_{x}=\overline{u C}=\bar{u} \bar{C}+\overline{\tilde{u}} \widetilde{C}+\overline{u^{\prime} C^{\prime}}=\bar{\phi}_{x}+\tilde{\phi}_{x}+\phi_{x}^{\prime}
$$

where the right-hand-side terms denote the net current-related, wave-related, and turbulent diffusive flux, respectively. The net total sand flux and the net flux components are shown in the lower panels in Fig. 5. Note the different scales for the horizontal axes.

At $x=51.0,53.0$ and $54.5 \mathrm{~m}$, i.e. locations in the shoaling region and in the breaking region offshore from the bar crest, the bed was plane. At these locations, the total net sand flux at outer-flow elevations $(\zeta>\delta)$ is offshore-directed and dominated by the current-related flux (offshore advection by undertow). However, inside the WBL $(\zeta<\delta)$, significant onshore-directed wave-related sand fluxes occur at all locations, which are explained by a higher suspended sediment load during the crest-phase than during the trough phase. Locally, the onshore wave-related flux can exceed the offshore current-related flux, leading to onshore-directed net total fluxes inside the WBL as opposed to offshore-directed fluxes at free-stream elevations (e.g. $x=51.0 \mathrm{~m}$ and $54.5 \mathrm{~m}$ ). The results are consistent with observations under non-breaking skewed waves over a plane bed, where the wave-related fluxes were also confined to the WBL (Schretlen, 2012).

At $x=56.0 \mathrm{~m}$, wave-related fluxes become significant also above the WBL $(\zeta>\delta)$, due to distinct phase variation of sediment concentration that extends to elevations outside the WBL. More detailed analysis (see Van der Zanden et al., Submitted) revealed that at this location, net pick-up occurred especially during the wave trough phase, which is likely due to the arrival of breaking-generated vortices 
during this wave phase. Sand particles are mobilized during the wave trough phase, are then advected upward to $\zeta>\delta$ by the orbital flow during the zero-up water surface elevation crossing (trough-to-crest flow reversal), and are finally transported onshore during the wave crest phase. Results at $x=56.0 \mathrm{~m}$ further reveal a net onshore diffusive flux $\phi^{\prime}{ }_{x}$, which is explained by the combination of high turbulence levels and steep cross-shore concentration gradients $-\mathrm{d} C / \mathrm{d} x$, leading to net diffusion in the direction of lowest concentration (here: onshore).
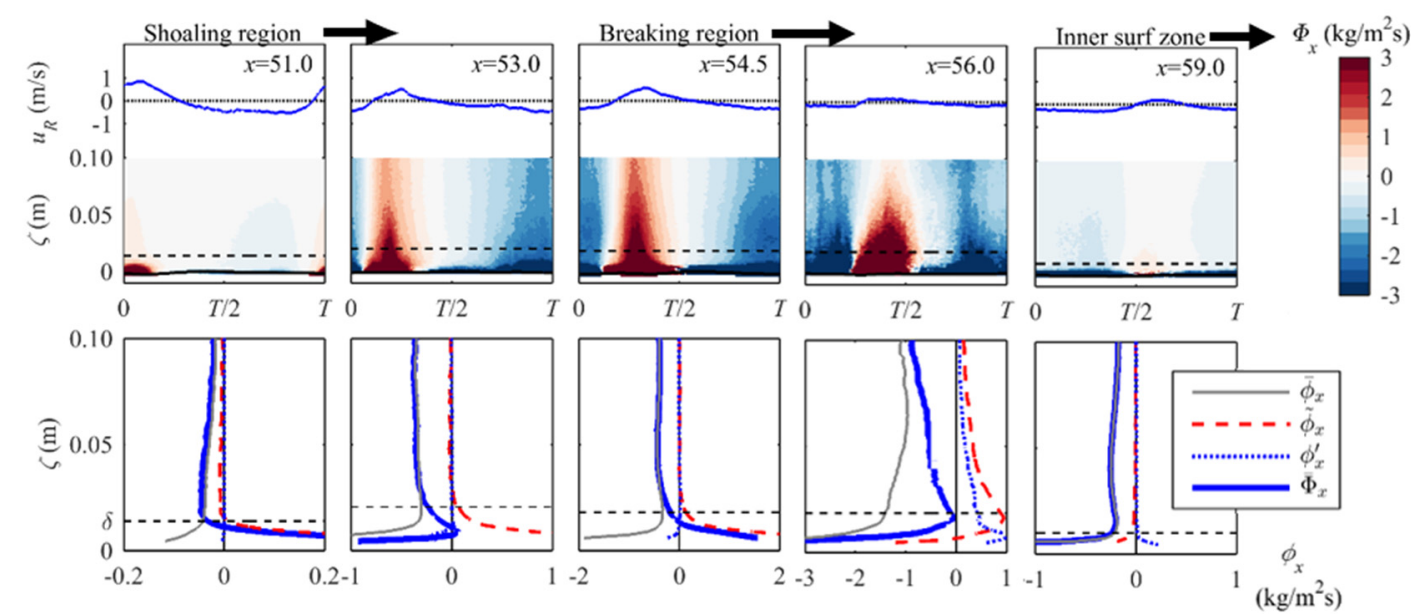

Figure 5. Horizontal sand flux near the bed $(\zeta=0.005$ to $0.10 \mathrm{~m})$ measured by ACVP at five cross-shore locations. Upper panels: phase-averaged free-stream bed-parallel velocity $u_{R}$ and phase-averaged total sand flux $\left\langle\Phi_{x}>=\left\langle u C>\right.\right.$. Lower panels: time-averaged sand flux $\bar{\Phi}_{\mathrm{x}}$, decomposed into a current-related flux $\bar{\phi}_{x}=\bar{u} \bar{C}$, a wave-related flux $\tilde{\phi}_{x}=\bar{u} \widetilde{C}$, and a turbulent diffusive flux $\phi_{x}^{\prime}=\overline{u^{\prime} C^{\prime}}$. Horizontal dashed line in each panel marks the WBL crest-phase overshoot elevation $\delta$, as proxy for WBL thickness.

We now extend the sand flux analysis to the whole water column. Total net sand fluxes were quantified by extrapolating the undertow profile up to wave crest level by fitting a quadratic distribution (based on work by Kobayashi et al., 2005), which was then multiplied with the time-averaged concentration profiles obtained through fitting Eq. 1 (more information is given by Van der Zanden et al., Submitted). Fig. 6 shows the spatial distribution of the horizontal sand flux. Note that the flux is the mean over the full wave period, i.e. using $\Phi_{x}=0$ for wave cycle instants with no water presence (between wave trough and crest level).

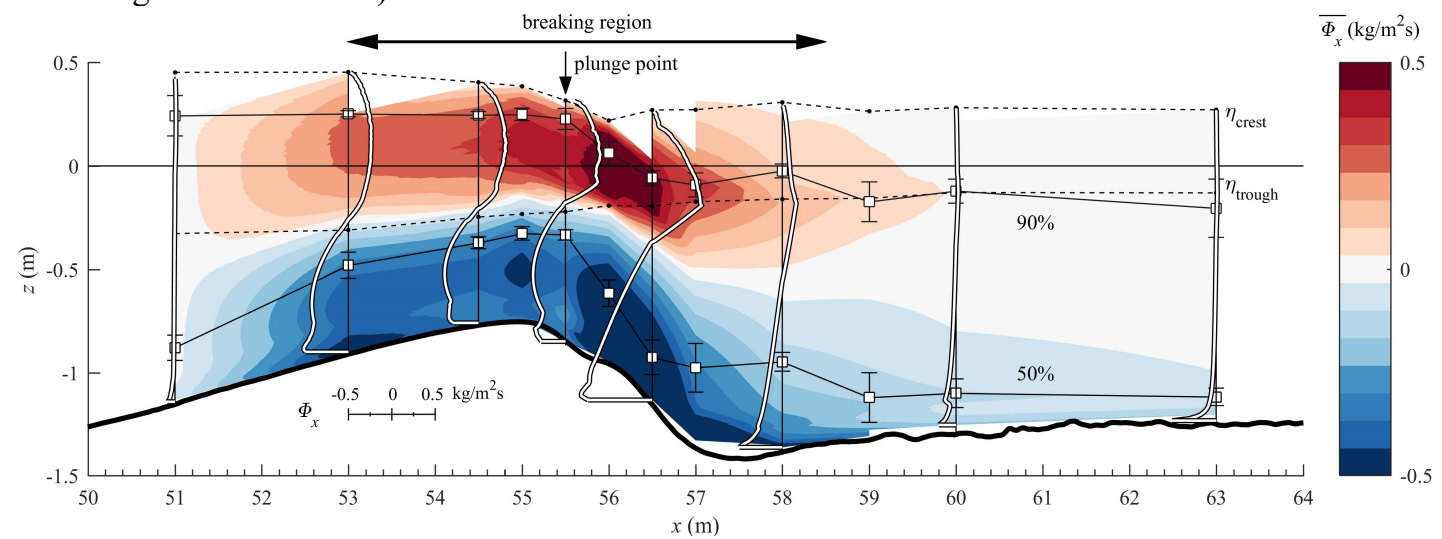

Figure 6. Vertical and horizontal distribution of the net total horizontal suspended sand flux.

The net total suspended sand flux shows a large spatial variation, with much higher flux magnitudes in the wave breaking region compared to the shoaling and inner surf zones. This is not only due to the much higher suspended sediment load, but also because of the high undertow velocities. Net fluxes are especially of high magnitude above the shoreward side of the breaker bar, between the bar crest and trough. Here, the strong undertow in combination with the high sediment load (due to enhanced sand pick-up and mixing by wave breaking turbulence) leads to strong offshore advection of suspended sand from the bar trough to the bar crest. 
Note further the high onshore-directed sand flux between wave trough and wave crest level above the breaker bar crest, which is due to the strong vertical mixing of suspended sediment. This onshore flux contributes significantly to the depth-integrated suspended sand transport.

Additional analysis revealed that over the surf zone the suspended sand flux in the WBL accounts for $10-20 \%$ of the depth-integrated suspended transport. Hence, the suspended sand transport is at all cross-shore locations dominated by fluxes at outer-flow elevations that account for $80-90 \%$ of the depthintegrated sand transport (see Van der Zanden et al., Submitted). This suggests that morhodynamic models especially require accurate formulations for the wave-averaged advection-diffusion of suspended sediment, e.g. for vertical mixing and for reference concentration.

\section{Sheet flow processes}

Shifting our attention from the suspension to the bedload layer, this section investigates sheet flow processes measured with $\mathrm{CCM}^{+}$at two cross-shore locations slightly offshore from the bar crest, at $x=$ $53.0 \mathrm{~m}$ (wave 'break point') and $54.5 \mathrm{~m}$ (between break point and splash point) (c.f. Fig. 1b). The CCM provides point measurements of sheet flow concentration, but by sampling at a different elevation for each wave cycle, the instrument can provide the intra-wave phase-averaged concentration field $\langle C(\zeta, t)>$. Additionally, intra-wave particle velocities were measured by cross-correlating concentration time series by two separated but closely spaced $(1.5 \mathrm{~cm})$ sensors. More details on the $\mathrm{CCM}^{+}$and the data treatment of sheet flow concentration measurements in the present experiment is given in Van der Zanden (2016) (Chapter 4).

Fig. 7 shows $\langle C(\zeta, t)>$ at both cross-shore locations, including the bottom and the top of the sheet flow layer, quantified by fitting the empirical curve by O'Donoghue and Wright (2004) through $<C(\zeta, t)>$ for each time instant $t / T$. The vertical distance between the two curves is the time-varying sheet flow layer thickness $\delta_{\mathrm{s}}$.
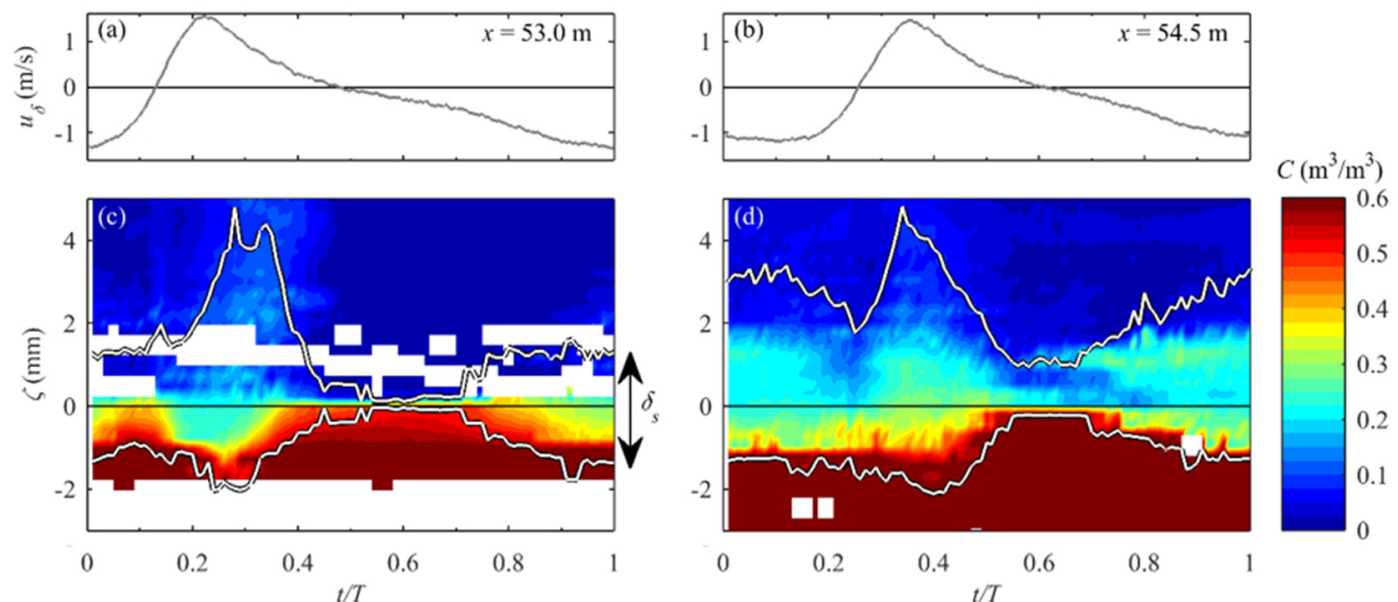

Figure 7. Sheet flow concentration measurements at $x=53.0 \mathrm{~m}$ (left) and $54.5 \mathrm{~m}$ (right). (a,b) Phase-averaged velocity by $A C V P$ at $\zeta=\delta$; (c,d) Phase-averaged sheet flow concentration by $C_{C} C^{+}$. White lines mark the bottom and top of the sheet flow layer, their vertical separation distance is the sheet flow layer thickness $\delta_{\mathrm{s}}$.

At both locations the sheet flow layer responds quasi-instantaneously to hydrodynamic forcing: the sheet flow layer increases at the start of each half cycle, and decreases in thickness as soon as magnitudes of velocity (and bed shear) stress reduce. Such a quasi-instantaneous response is consistent with previous observations of medium-sand sheet flow under non-breaking waves (e.g. Schretlen, 2012) and in oscillatory flows (e.g. O'Donoghue and Wright, 2004). The sheet flow layer comes almost fully to rest during the crest-to-trough flow reversal $\left(\delta_{\mathrm{s}} \leq 1 \mathrm{~mm}\right)$, but this is not the case for the trough-to-crest flow reversal. This is explained by the relatively short duration between high offshore-directed and high onshore-directed velocities for acceleration-skewed oscillatory flows, which allows little time for mobilized sediment to completely settle down (Watanabe and Sato, 2004; Ruessink et al., 2011).

At both locations, but in particular at $x=53.0 \mathrm{~m}$, the sheet flow layer thickness is significantly higher during the crest phase than during the trough phase. This may be expected for the present asymmetric waves, which induce a near-bed flow with strong positive periodic-velocity and acceleration skewness; previous observations under velocity-skewed non-breaking flows (Schretlen, 2012) and accelerationskewed oscillatory flows in tunnels (Ruessink et al., 2011) also observed higher crest-phase sheet flow 
thickness. Note that the higher crest-phase sheet flow thickness in the present study occurs despite an offshore-directed time-averaged undertow velocity of moderate magnitude $(\bar{u}=-0.2 \mathrm{~m} / \mathrm{s}$ at $\zeta=0.1 \mathrm{~m})$.

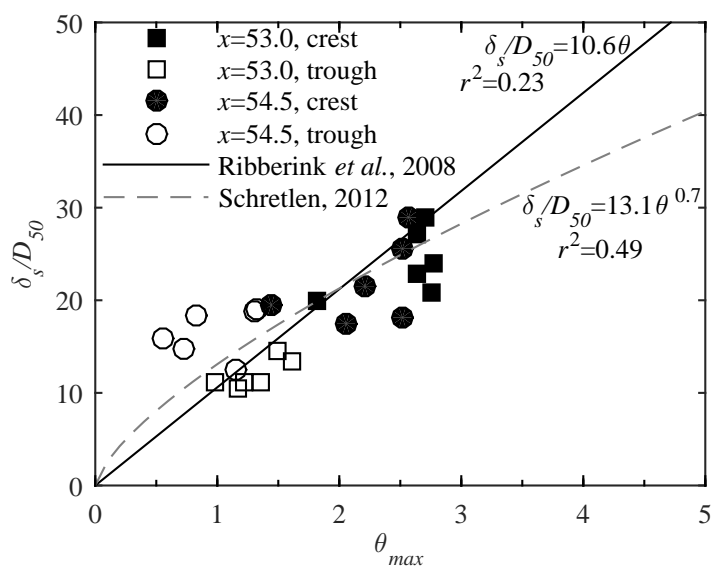

Figure 8. Maximum sheet flow layer thickness versus maximum Shields stress per wave half-cycle, including empirical relations by Ribberink et al. (2008) (solid line) and Schretlen (2012) (dashed line).

The relation between sheet flow layer thickness and velocity forcing is examined through Fig. 8, which shows the maximum sheet flow layer thickness and the maximum estimated Shields parameter $\theta_{\max }$ for each half wave cycle and for both cross-shore locations. $\theta_{\max }$ was calculated based on ACVP measurements using empirical formulations as detailed in Van der A et al. (2013). Note that the accordingly calculated $\theta_{\max }$ values explicitly account for acceleration-skewness effects through the wave friction factor (see Van der A et al., 2013). Fig. 8 includes two empirical relations for the maximum sheet flow layer thickness, based on detailed measurements in oscillatory flow tunnel (Ribberink et al., 2008) and wave flume (Schretlen, 2012) conditions.

Fig. 8 shows that the half-cycle maximum sheet flow layer thickness increases with Shields parameter, which is consistent with a quasi-instantaneous sheet flow layer response (i.e. no significant phase lags). The measured sheet flow layer thicknesses are predicted reasonably well by the two empirical equations. This shows that the sheet flow thickness under the strongly asymmetric and breaking waves in the present study responds similarly to hydrodynamic forcing as sheet flow layers under nonbreaking waves and in oscillatory tunnel conditions. Apparently, effects of wave breaking turbulence and of strong horizontal pressure gradients (c.f. Sleath, 1999) near the bar crest do not produce thicker phaseaveraged sheet flow layers compared to previous non-breaking wave and tunnel observations of oscillatory sheet flow. This suggests that existing models for sheet flow (bedload) transport, that have been developed for non-breaking wave conditions, may also be used for surf zone conditions.

\section{Net sand transport and breaker bar morphodynamics}

This section discusses the morphologic evolution of the breaker bar in relation to net sand transport rates across the test section.

During the 90-minute experiment, the breaker bar crest increased while its trough deepened (Fig. $9 \mathrm{~d}$ ). In addition, the offshore slope of the bar eroded (for $x<51.0 \mathrm{~m}$ ) and steepened. The net total transport $q_{\text {tot}}$, inferred from the bed profile evolution through solving a mass conservation equation, is shown in Fig. 9a (dashed line). The morphologic evolution of the breaker bar is explained by onshore-directed $q_{\text {tot }}$ at $x<54.5 \mathrm{~m}$ and offshore-directed $q_{\text {tot }}$ for $x>54.5 \mathrm{~m}$. The reversal from onshore to offshore $q_{\text {tot }}$ occurs in the wave breaking region; the steep cross-shore gradients in this region ( $x=53.0$ to $58.5 \mathrm{~m})$ relate directly to the strongly non-uniform hydrodynamic conditions around the breaker bar under the breaking wave.

The total net sand transport rate was decomposed into three contributions:

- $q_{\mathrm{s}, \mathrm{w}}$ : the net wave-related suspended transport rate, which is significant only close to the bed and which is obtained by depth-integrating (from $\zeta=z_{\mathrm{a}}$ to $0.10 \mathrm{~m}$ ) the wave-related suspended fluxes measured with ACVP;

- $q_{\mathrm{s}, \mathrm{c}}$ : the net current-related suspended transport rate, obtained by depth-integrating (from $\zeta=z_{\mathrm{a}}$ to $\left.\eta_{\text {crest }}\right)$ the current-related flux profile that was estimated from inter- and extrapolated undertow and concentration profiles based on ACVP, ADV and TSS measurements (c.f. Fig. 6); 
- $\quad q_{\text {bed: }}$ the bedload transport or 'rest' term, i.e. $q_{\text {bed }}=q_{\text {tot }}-q_{\mathrm{s}}$, where $q_{\mathrm{s}}$ is the net suspended sand transport rate that involves wave-related, current-related and measured diffusive contributions.

Fig. 9a includes the cross-shore distribution of each transport component. Reference is also made to Table 1, which shows the mean transport rate of each component for the shoaling zone, breaking zone, and inner surf zone. Table 1 also includes the relative importance of each component, quantified by dividing the absolute value of each component by the sum of absolute values of all components, $q_{\Sigma}(=$ $\left.\left|q_{\text {bed }}\right|+\left|q_{\mathrm{s}, \mathrm{c}}\right|+\left|q_{\mathrm{s}, \mathrm{w}}\right|\right)$.

\begin{tabular}{|c|c|c|c|c|c|c|c|}
\hline Locations & $\begin{array}{c}q_{\text {bed }}{ }^{*} 10^{5} \\
\left(\mathrm{~m}^{2} / \mathrm{s}\right)\end{array}$ & $\begin{array}{c}q_{\mathrm{s}, \mathrm{w}}{ }^{*} 10^{5} \\
\left(\mathrm{~m}^{2} / \mathrm{s}\right)\end{array}$ & $\begin{array}{c}q_{\mathrm{s}, \mathrm{c}}{ }^{*} 10^{5} \\
\left(\mathrm{~m}^{2} / \mathrm{s}\right)\end{array}$ & $\begin{array}{l}q_{\mathrm{tot}} * 10^{5} \\
\left(\mathrm{~m}^{2} / \mathrm{s}\right)\end{array}$ & $\left|q_{\text {bed }}\right| / q_{\Sigma}$ & $\left|q_{\mathrm{s}, \mathrm{w}}\right| / q_{\Sigma}$ & $\left|q_{\mathrm{s}, \mathrm{c}}\right| / q_{\Sigma}$ \\
\hline $\begin{array}{l}x \leq 53.0 \mathrm{~m} \\
\text { (shoaling zone) }\end{array}$ & $4.9 \pm 1.5$ & $0.3 \pm 0.3$ & $-1.6 \pm 1.5$ & $3.6 \pm 1.3$ & $76 \pm 16 \%$ & $5 \pm 4 \%$ & $20 \pm 14 \%$ \\
\hline $\begin{array}{c}53.0 \mathrm{~m}<x \leq 58.5 \mathrm{~m} \\
\text { (breaking zone) }\end{array}$ & $2.0 \pm 2.8$ & $0.5 \pm 1.0$ & $-5.2 \pm 4.1$ & $-2.6 \pm 2.0$ & $29 \pm 13 \%$ & $8 \pm 9 \%$ & $63 \pm 12 \%$ \\
\hline $\begin{array}{l}x>58.5 \mathrm{~m} \\
\quad \text { (inner surf zone) }\end{array}$ & $0.7 \pm 1.3$ & $0.0 \pm 0.1$ & $-2.2 \pm 1.2$ & $-1.5 \pm 1.0$ & $29 \pm 18 \%$ & $2 \pm 4 \%$ & $69 \pm 18 \%$ \\
\hline
\end{tabular}

The bedload transport $q_{\text {bed }}$ is onshore-directed at almost all locations. High $q_{\text {bed }}$ occurs in the shoaling region $(x=51.0-53.0 \mathrm{~m})$; with bedload transport in the sheet flow regime, the transport is onshore due to the strongly velocity- and acceleration-skewed near-bed flow. At these locations, $q_{\text {bed }}$ is the dominant contributor to total transport. At the bar crest $(x=54.5-55.5 \mathrm{~m}) q_{\text {bed }}$ magnitudes decrease, due to an increase in undertow velocity magnitude and to a decrease in acceleration skewness relative to $x=51.0$ and $53.0 \mathrm{~m}$. A local increase in $q_{\text {bed }}$ occurs between the bar crest and trough $(x=56.0-57.0 \mathrm{~m})$ due to the steep bed slope which promotes downslope onshore bedload transport. In the inner surf zone $(x>$ $58.5 \mathrm{~m}), q_{\text {bed }}$ is onshore-directed but of small magnitude.

The suspended load transport rate $q_{\mathrm{s}}$ is at all locations offshore-directed and dominated by the current-related component $q_{\mathrm{s}, \mathrm{c}}$. Magnitudes of $q_{\mathrm{s,c}}$ are small in the shoaling region, but increase strongly in the wave breaking region $(x=53.0-58.5 \mathrm{~m})$, with particularly high magnitudes along the shoreward slope of the breaker bar $(x=56.0-57.0 \mathrm{~m})$. Suspended sand transport dominates the total transport at locations shoreward from the break point, with magnitudes of $q_{\mathrm{s}, \mathrm{c}}$ that exceed values of $q_{\mathrm{bed}}$ by about a factor two (Table 1).

The wave-related transport $q_{\mathrm{s}, \mathrm{w}}$ is at all locations onshore-directed but of smaller magnitude than $q_{\mathrm{s}, \mathrm{c}}$ and $q_{\text {bed. }}$. Nevertheless, the contributions by $q_{\mathrm{s}, \mathrm{w}}$ can locally reach up to $20 \%$ of $q_{\Sigma}$ and can therefore not be neglected. Magnitudes of $q_{\mathrm{s}, \mathrm{w}}$ increase from shoaling to breaking region, possibly due to enhancing wave breaking turbulence effects on the intra-wave time-varying pick-up.

Fig. $9 \mathrm{~b}$ finally shows the measured rate of bed level change (dashed line), and the contributions of the bedload and suspended load transport to bed level changes. The latter two are quantified based on their cross-shore gradients as $-1 /\left(1-\varepsilon_{0}\right) \mathrm{d} q / \mathrm{d} x$, where $\varepsilon_{0}=0.4$ is the porosity of the loosely packed sand bed. Bedload and suspended load transport both affect the breaker bar morphologic evolution, yet their effects are nearly opposite.

The bedload transport component leads to net erosion of the offshore slope and to net deposition around $x=54.0 \mathrm{~m}$, slightly offshore from the bar crest $\left(-\mathrm{d} q_{\text {bed }} / \mathrm{d} x>0\right)$. This erosion-deposition pattern is responsible for the steepening of the offshore slope during the experiment and contributes to breaker bar growth. Bedload transport further leads to erosion at the higher sections of the breaker bar's shoreward slope $(x=55.5-56.5 \mathrm{~m})$; this eroded sediment is deposited at the lower sections of the slope and at the bar trough $(x=56.5-58.0 \mathrm{~m})$.

Suspended load sand transport erodes the trough of the breaker bar $\left(-\mathrm{d} q_{\mathrm{s}} / \mathrm{d} x<0\right)$, which can be explained by the local combination of enhanced pick-up by breaking generated turbulence and a strong undertow that promotes offshore sand advection rates. The entrained particles are advected offshore and upward along the shoreward slope of the bar and settle down at the bar crest, where both undertow magnitudes and TKE levels decrease. Hence, suspended load transport induces erosion of the bar trough and growth of the bar crest. 

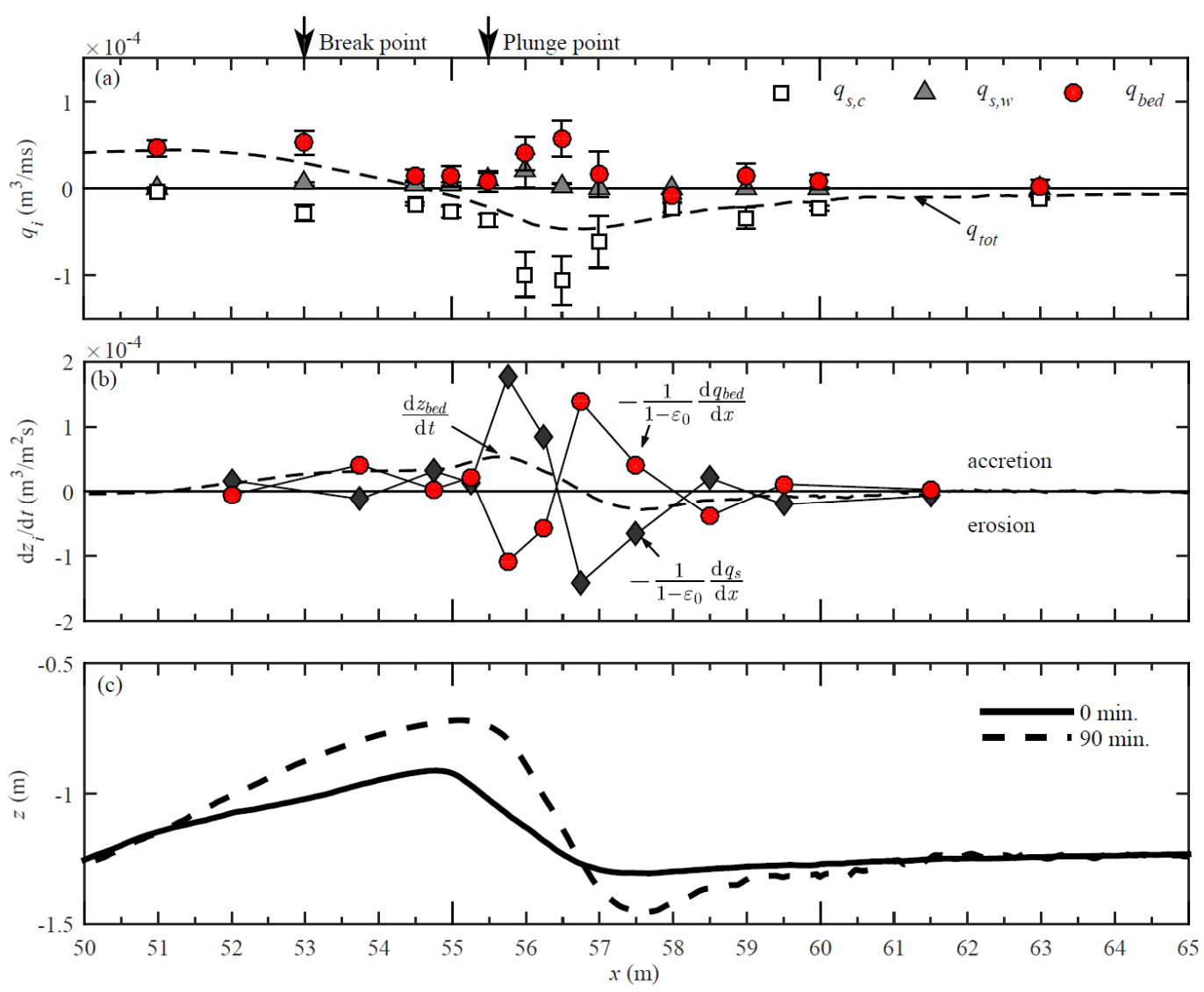

Figure 9. Net sand transport rates across the test section. (a) Net sand transport rates, distinction is made between total transport (dashed black line), bedload transport (circles), current-related suspended sand transport (squares) and wave-related suspended transport (diamonds); (b) Contribution of each transport component to local bed level change; (c) Bed profile at start (solid) and end (dashed) of experiment. Values in $(a, b)$ are means over six runs per location, with error bars in (a) marking the $95 \%$ confidence interval.

\section{DISCUSSION}

The present experiment sheds more insights in the complex sand transport dynamics under plunging breaking waves around a breaker bar, yet some remarks should be placed concerning the experimental conditions. The choice for monochromatic waves leads to a strong undertow and to cross-shore gradients in time-averaged velocity statistics (undertow velocity, wave shape asymmetry) and total net transport rates that are much steeper than for irregular waves. Consequently, the obtained sandbar profile has steeper offshore and onshore slopes than typical breaker bars in the field. These steep slopes directly affect the bedload transport, but also contribute to flow non-uniformity which affects the suspended load transport.

Also the chosen wave period $(T=4 \mathrm{~s})$ affects the results importantly. Compared to other experimental observations, the present plunging wave induces limited temporal intra-wave variation in TKE. This is partly ascribed to the bar-trough geometry, which allows the formation of turbulent vortices with larger scale compared to plane-bed studies (Van der A et al., Submitted), but also relates to the wave period: waves with larger wave period will yield more intra-wave TKE variation. This is especially important for the wave-related advection of suspended sand, which shows a strong coupling with the spatiotemporal variation of TKE (Van der Zanden et al., Submitted). Waves with stronger intra-wave variation in TKE are expected to yield more intra-wave variation of suspended sediment concentration, because turbulence affects not only the intra-wave sediment pick-up but it also hinders the settling of suspended sand grains. The significance of the net wave-related flux is likely affected by the ratio of a suspended particle settling time over the wave period. Longer-period plunging waves or coarser sediment are expected to produce higher net wave-related suspended sediment fluxes. This may explain differences between the present experiment and previous studies that found larger contributions of the high- 
frequency wave-related suspended transport component (Houwman and Ruessink, 1996; Brinkkemper et al., 2017).

Wave breaking effects on the wave-related suspended sand transport $q_{\mathrm{s}, \mathrm{w}}$ could be accounted for either in sand transport models for the 'near-bed load' (e.g. Van der A et al., 2013) or included into waveaveraged advection-diffusion models for suspended sediment (e.g. Van Rijn, 2007). Wave breaking may promote $q_{\mathrm{s}, \mathrm{w}}$ either in onshore or offshore direction depending on the phase coupling of wave breaking turbulence near the bed, which depends on breaker type (Ting and Kirby, 1996) and which varies greatly across the surf zone (Boers, 2005; Van der A et al., Submitted). The direction of $q_{\mathrm{s}, \mathrm{w}}$ can be controlled through phase lag parameters (e.g. Van der A et al., 2013; Van Rijn, 2007). The further development of parameterizations for wave breaking effects on $q_{\mathrm{s}, \mathrm{w}}$ would benefit from high-resolution measurements for a wider wave condition and sediment parameter space, but could also be developed on the basis of sophisticated intra-wave numerical models (e.g. Jacobsen and Fredsoe, 2014).

For the present study, suspended transport is dominated by current-related advection and a numerical reproduction would require an accurate description of undertow profiles and of sediment concentration profiles. The latter depends greatly on precise models for sediment mixing and for the reference concentration or sediment pick-up rate. The present study suggests a strong effect of wave breaking turbulence on the wave-averaged reference concentration, which is not accounted for in most common reference concentration models (e.g. Nielsen, 1986; Van Rijn, 2007). Parameterizations for wave breaking effects on sediment pick-up or reference concentration have been proposed, for instance by adding TKE to bed shear stress (Hsu and Liu, 2004; Okayasu et al., 2010), by directly relating $C_{0}$ to turbulence (Steetzel, 1993), or by relating pick-up or reference concentration to breaking wave characteristics (Mocke and Smith, 1992; Kobayashi and Johnson, 2001; Spielmann et al., 2004). However, none of these studies have led to a widely applied model for wave breaking effects on sediment pick-up, and the validation of these existing parameterizations against a wide range of surf zone suspension measurements seems a crucial next step in advancing suspended sand transport modeling.

The measurements suggest a significant onshore suspended flux contribution between wave trough and crest level. Omission of this flux contribution would overestimate offshore-directed suspended transport rate magnitudes, and would also hamper predictions of the suspended sediment concentration profiles above wave trough level where a significant influx of sediment at the water surface would be neglected. A straightforward way to account for this sand flux would be multiplying the concentration at the water surface with the onshore fluid mass flux associated with the Stokes drift and surface roller. However, such an approach would require good estimates of the concentration at the water surface, which in return requires accurate formulations for sand pick-up and vertical mixing.

It is finally noted that challenges in modeling surf zone sand transport not only lie in advancing sand transport models, but also in hydrodynamic models. Firstly, an appropriate modeling of undertow is not only important for the horizontal advection of suspended sediment, but also to predict the vertical advection of suspended grains by the two-dimensional (cross-shore and vertical) undertow circulation. Secondly, the modeling of sand suspension requires an accurate description of sediment diffusivity profiles, which in return requires high-quality TKE profiles. The latter is also required when incorporating TKE effects into reference concentration models. However, an appropriate quantitative description of surf zone TKE is not trivial for present turbulence closure models (Brown et al., 2016). Thirdly, wave breaking leads to large local deformations of the wave shape, which are especially important in terms of bedload-driven bed level changes around the breaker bar. Parameterizations for orbital velocity skewness and asymmetry generally cannot predict such local changes in the wave breaking region (Ruessink et al., 2012), although a recent alternative shows promising improvements in terms of wave shape statistics near the breaking point (Rocha et al., 2017).

\section{CONCLUSIONS}

Suspended and bedload transport processes were measured in a large-scale wave flume around a medium-sand breaker bar under plunging breaking waves. We obtained measurements of outer-flow and wave bottom boundary layer (WBL) velocity, turbulence, suspended sand concentration, suspended sand fluxes, sheet flow layer concentrations, and of bed profile evolution and net bedload, suspended load and total load sand transport rates. The detailed insights lead to the following conclusions with implications for sediment transport modeling:

1. Reference concentrations correlate poorly with orbital velocity, but instead, correlate significantly with near-bed turbulent kinetic energy. Omitting such wave breaking turbulence effects in models 
for reference concentration or pick-up rates may lead to a major underestimation of the suspended sediment load.

2. Wave-averaged reference concentrations are largely $(>90 \%)$ controlled by local pick-up. This supports the use of reference concentration models based on local hydrodynamic forcing.

3. Suspended sediment is especially well-mixed above the bar crest. The high vertical mixing likely has both diffusive (by breaking-generated turbulence) and advective (by upward-directed timeaveraged velocity resulting from a two-dimensional undertow circulation) nature.

4. The suspended sand transport between wave trough and wave crest level, i.e. including the sediment flux contained in the surface roller, contributes significantly to total net transport and should not be omitted in suspended sand transport models for the surf zone.

5. Net suspended sand transport at outer-flow elevations is almost fully current-related (i.e. undertowdominated); the wave-related contribution is generally negligible. This supports the use of waveaveraged advection-diffusion models for the outer flow. The measured turbulent diffusive fluxes are much smaller than the advective fluxes.

6. Net WBL sand fluxes can be onshore-directed despite offshore-directed free-stream undertow velocity. This is explained by high onshore wave-related fluxes that are generally confined to the WBL, consistent with non-breaking wave observations. In the breaking region, the suspended load increases at outer-flow elevations and inside the WBL, leading to an increase in the current-related suspended sand flux but also in the wave-related suspended flux. These wave-related flux contributions can either be incorporated in a suspended sediment transport model or in a local 'bedload + near-bed transport' model.

7. The sheet flow layer responds quasi-instantaneously to local velocity forcing. The maximum phaseaveraged sheet flow layer thickness is quantitatively similar to previous observations in oscillatory tunnels and under non-breaking waves. Effects of wave breaking turbulence on sheet flow concentration, thickness and horizontal fluxes are not evident. This suggests that existing bedload transport models may also be valid at breaker bars.

8. Bedload transport around the bar crest is directed onshore, despite a moderate offshore-directed undertow velocity (up to $-0.2 \mathrm{~m} / \mathrm{s}$ at $z-z_{\text {bed }}=0.1 \mathrm{~m}$ ) and a shoreward-tilted bed slope offshore from the bar crest $\left(\mathrm{d} z_{\text {bed }} / \mathrm{d} x \approx 1: 10\right)$; this onshore bedload transport is driven by wave shape asymmetry (inducing a near-bed flow with high velocity and acceleration skewness).

9. The breaker bar bed evolution is explained by onshore-directed bedload and offshore-directed suspended load transport, which are of similar magnitude but have opposing effects on bar morphology.

\section{ACKNOWLEDGMENTS}

The research presented in this paper is conducted within the SINBAD project, funded by STW (12058) and EPSRC (EP/J00507X/1, EP/J005541/1), and received additional funding through the European Community's FP7 project Hydralab IV (contract no. 261520).

\section{REFERENCES}

Boers, M. 2005. Surf zone turbulence. PhD Thesis, TU Delft, The Netherlands.

Brinkkemper, J. A., A. T. M. de Bakker and B. G. Ruessink. 2017. Intrawave sand suspension in the shoaling and surf zone of a field-scale laboratory beach. Journal of Geophysical Research: Earth Surface.

Brown, S. A., D. M. Greaves, V. Magar and D. C. Conley. 2016. Evaluation of turbulence closure models under spilling and plunging breakers in the surf zone. Coastal Engineering 114, 177-193.

Cox, D. T., N. Kobayashi and A. Okayasu 1996. Bottom shear stress in the surf zone. Journal of Geophysical Research-Oceans 101(C6), 14337-14348.

Fernández-Mora, A., D. Calvete, A. Falqués and H. E. de Swart. 2015. Onshore sandbar migration in the surf zone: New insights into the wave-induced sediment transport mechanisms. Geophysical Research Letters 42(8), 2869-2877.

Hoefel, F. and S. Elgar. 2003. Wave-induced sediment transport and sandbar migration. Science 299(5614), 1885-1887.

Houwman, K. T. and G. Ruessink. 1996. Cross-shore sediment transport mechanisms in the surfzone on a timescale of months to years. Proceedings of the $25^{\text {th }}$ International Conference on Coastal Engineering, ASCE, 4793-4806. 
Hsu, T. J. and P. L. F. Liu. 2004. Toward modeling turbulent suspension of sand in the nearshore. Journal of Geophysical Research-Oceans 109(C6).

Hurther, D., P. D. Thorne, M. Bricault, U. Lemmin and J. M. Barnoud. 2011. A multi-frequency Acoustic Concentration and Velocity Profiler (ACVP) for boundary layer measurements of fine-scale flow and sediment transport processes. Coastal Engineering 58(7), 594-605.

Jacobsen, N. G. and J. Fredsoe. 2014. Formation and development of a breaker bar under regular waves. Part 2: Sediment transport and morphology. Coastal Engineering 88, 55-68.

Kobayashi, N. and B. D. Johnson. 2001. Sand suspension, storage, advection, and settling in surf and swash zones. Journal of Geophysical Research 106(C5), 9363-9376.

Kobayashi, N., H. Zhao and Y. Tega. 2005. Suspended sand transport in surf zones. Journal of Geophysical Research 110(C12).

Luijendijk, A. P., R. Ranasinghe, M. A. de Schipper, B. A. Huisman, C. M. Swinkels, D. J. R. Walstra and M. J. F. Stive. 2017. The initial morphological response of the Sand Engine: A process-based modelling study. Coastal Engineering 119, 1-14.

Mocke, G. P. and G. G. Smith. 1992. Wave breaker turbulence as a mechanism for sediment suspension. Proceedings of the 23rd International Conference on Coastal Engineering. ASCE, 2279-2292.

Nadaoka, K., S. Ueno and T. Igarashi. 1988. Sediment suspension due to large scale eddies in the surf zone. Proceedings of the 21st International Conference on Coastal Engineering. ASCE, 1646-1660.

Nielsen, P. 1984. Field-Measurements of Time-Averaged Suspended Sediment Concentrations under Waves. Coastal Engineering 8(1), 51-72.

Nielsen, P. 1986. Suspended Sediment Concentrations under Waves. Coastal Engineering. 10(1), 23-31.

O'Donoghue, T. and S. Wright 2004. Concentrations in oscillatory sheet flow for well sorted and graded sands. Coastal Engineering 50(3), 117-138.

Okayasu, A., K. Fujii and M. Isobe. 2010. Effect of external turbulence on sediment pickup rate. Proceedings of the $32^{\text {nd }}$ International Conference on Coastal Engineering, CERC, 13 pp.

Ribberink, J. S., J. J. van der Werf, T. O'Donoghue and W. N. M. Hassan. 2008. Sand motion induced by oscillatory flows: Sheet flow and vortex ripples. Journal of Turbulence 9(20), 1-32.

Ribberink, J. S., D. A. Van der A, J. Van der Zanden, T. O'Donoghue, D. Hurther, I. Cáceres and P. D. Thorne. 2014. SandT-Pro: Sediment transport measurements under irregular and breaking waves. Proceedings of the 34th International Conference on Coastal Engineering. CERC, 14 p.

Rocha, M. V. L., H. Michallet and P. A. Silva. 2017. Improving the parameterization of wave nonlinearities - The importance of wave steepness, spectral bandwidth and beach slope. Coastal Engineering 121, 77-89.

Ruessink, B. G., H. Michallet, T. Abreu, F. Sancho, D. A. Van der A, J. J. Van der Werf and P. A. Silva. 2011. Observations of velocities, sand concentrations, and fluxes under velocity-asymmetric oscillatory flows. Journal of Geophysical Research 116(C3).

Ruessink, B. G., G. Ramaekers and L. C. van Rijn. 2012. On the parameterization of the free-stream nonlinear wave orbital motion in nearshore morphodynamic models. Coastal Engineering 65, 56-63.

Schretlen, J. L. M. 2012. Sand transport under full-scale progressive surface waves. PhD Thesis, University of Twente, The Netherlands.

Scott, N. V., T. J. Hsu and D. Cox. 2009. Steep wave, turbulence, and sediment concentration statistics beneath a breaking wave field and their implications for sediment transport. Continental Shelf Research. 29(20), 2303-2317.

Sleath, J. F. A. 1999. Conditions for plug formation in oscillatory flow. Continental Shelf Research 19(13), 1643-1664.

Spielmann, K., D. Astruc and O. Thual. 2004. Analysis of some key parametrizations in a beach profile morphodynamical model. Coastal Engineering 51(10), 1021-1049.

Steetzel, H. 1993. Cross-shore transport during storm surges. $\mathrm{PhD}$ thesis, TU Delft, the Netherlands.

Sumer, B. M., H. A. A. Guner, N. M. Hansen, D. R. Fuhrman and J. Fredsøe. 2013. Laboratory observations of flow and sediment transport induced by plunging regular waves. Journal of Geophysical Research: Oceans 118(11), 6161-6182.

Svendsen, I. A., P. A. Madsen and J. Buhr Hansen. 1978. Wave characteristics in the surf zone. Proceedings of the 16th Conference on Coastal Engineering. ASCE, 520-539.

Ting, F. C. K. and J. T. Kirby 1996. Dynamics of surf-zone turbulence in a spilling breaker. Coastal Engineering 27(3-4), 131-160.

Van der A, D. A., J. S. Ribberink, J. J. van der Werf, T. O'Donoghue, R. H. Buijsrogge and W. M. Kranenburg. 2013. Practical sand transport formula for non-breaking waves and currents. Coastal Engineering 76, 26-42. 
Van der A, D. A., J. Van der Zanden, T. O'Donoghue, I. Cáceres, S. J. McLelland and J. S. Ribberink. Submitted. Hydrodynamics and turbulence under a large-scale plunging wave over a fixed bar. Journal of Geophysical Research: Oceans.

Van der Zanden, J. 2016. Sand Transport Processes in the Surf and Swash Zones. PhD Thesis, University of Twente, the Netherlands, $202 \mathrm{pp}$.

Van der Zanden, J., J. M. Alsina, I. Cáceres, R. H. Buijsrogge and J. S. Ribberink. 2015. Bed level motions and sheet flow processes in the swash zone: Observations with a new conductivity-based concentration measuring technique (CCM+). Coastal Engineering 105, 47-65.

Van der Zanden, J., D. A. van der A, D. Hurther, I. Cáceres, T. O'Donoghue and J. S. Ribberink. 2016. Near-bed hydrodynamics and turbulence below a large-scale plunging breaking wave over a mobile barred bed profile. Journal of Geophysical Research: Oceans 121(8), 6482-6506.

Van der Zanden, J., D. A. Van der A, D. Hurther, I. Cáceres, T. O'Donoghue and J. S. Ribberink. Submitted. Suspended sediment transport around a large-scale laboratory breaker bar. Coastal Engineering.

Van Rijn, L. C. 2007. Unified View of Sediment Transport by Currents and Waves. II: Suspended Transport. Journal of Hydraulic Engineering 133(6), 668-689.

van Rijn, L. C., J. S. Ribberink, J. J. van der Werf and D. J. R. Walstra. 2013. Coastal sediment dynamics: recent advances and future research needs. Journal of Hydraulic Research 51(5), 475-493.

Walstra, D. J. R., A. J. H. M. Reniers, R. Ranasinghe, J. A. Roelvink and B. G. Ruessink. 2012. On bar growth and decay during interannual net offshore migration. Coastal Engineering 60, 190-200.

Watanabe, A. and S. Sato. 2004. A sheet-flow transport rate for asymmetric, forward-leaning waves and currents. Proceedings of the 29th International Conference on Coastal Engineering, World Scientific, 1703-1714.

Yoon, H. D. and D. T. Cox. 2012. Cross-shore variation of intermittent sediment suspension and turbulence induced by depth-limited wave breaking. Continental Shelf Research 47, 93-106.

Zhou, Z., T.-J. Hsu, D. Cox and X. Liu. 2017. Large-eddy simulation of wave-breaking induced turbulent coherent structures and suspended sediment transport on a barred beach. Journal of Geophysical Research: Oceans. 